British Journal of Psychiatry (1994), 164, 697-710

\title{
Correspondence
}

Contents: Points of style/Malignant alienation/ Managing the manipulative therapist/Treating negative symptoms/Tardive dyskinesia as a risk factor for negative symptoms/Low serum cholesterol and suicide attempts/Verbal fluency and semantic memory in schizophrenia/Severity and the stressor criterion in post-traumatic stress disorder/ Diogenes syndrome by proxy/How abuse has affected me/Estimates of risks in relatives of psychotic probands/Childhood sexual abuse and mental health/All that tics may not be Tourette's/Brain, mind and behaviour/Cyclic psychosis, menstrual cycle and adolescence

\section{Points of style}

SIR: We welcome the introduction of structured summaries to the $B J P$ (Editorial, $B J P$, January $1994,164,1)$ but suggest a further alteration to style. The Method and Results sections of papers describing original research should be printed in the same size of type as for review articles and for the Introduction and Discussion of research papers.

In our teaching and supervision of research we emphasise that the method is the most important part of any study, and merits the most careful attention to detail. However, in our postgraduate seminars we find that the Method section of published research is too often incomprehensible or insufficiently detailed to allow critical appraisal. We suspect that one reason for this is the practice of printing the Method in a smaller typeface - with the implication that it is less important or will be of interest only to a few readers.

Many scientific journals allow the Method prominence equal to that of the rest of the paper. We examined the layout of the two main UK weekly medical journals and the 11 prominent specialist journals readily available in our library. While the $B J P$ is not alone in its use of smaller typeface for Method and Results, the majority of other relevant journals do give equal prominence to all parts of a research paper.

A small increase in size of Method and Results may cause pressure on space. However, in many papers the introductory remarks and the discussion would benefit from being shortened - or perhaps printed in smaller typeface! At least this practice would discourage the risky strategy of browsing through papers for the 'bottom line' as given by the authors in the Summary or Discussion.

Critical appraisal of the medical literature is a necessary skill for clinicians, and for those purchasing care for patients (Sackett $e t$ al, 1992; Sheldon $e t$ al, 1993). In taking up our suggestion, the BJP would take a small step in encouraging psychiatrists to develop that skill.

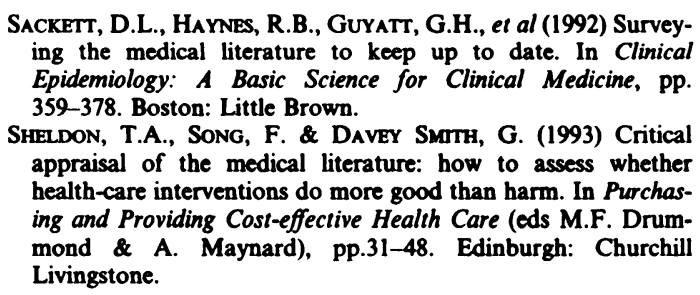

Sheldon, T.A., SONG, F. \& DAvey Smath, G. (1993) Critical appraisal of the medical literature: how to assess whether health-care interventions do more good than harm. In Purchasing and Providing Cost-effective Health Care (eds M.F. Drummond \& A. Maynard), pp.31-48. Edinburgh: Churchill Livingstone.

DAVID OWENS

Allan House

SIMON HATCHER

Division of Psychiatry and Behavioural Sciences University of Leeds

LS2 9LT

EDITOR'S REPLY: From the July issue of the BJP, the Method and Results sections will appear in the larger type.

\section{Malignant alienation}

SIR: At a time when the government has set targets for reducing rates of suicide it is unhelpful for Watts \& Morgan (BJP, January 1994, 164, 11-15) to provide it with a ready scapegoat - mental health professionals-should these targets fail to be achieved. The medicolegal consequences of their thesis, moreover, were it to be generally accepted, would be dire, since it provides a clear and direct rationale for negligence actions against psychiatric staff caring for patients who have committed suicide. 